\title{
Commentary: Don't try this at home $(?)$
}

\section{Alan D. L. Sihoe, FRCSEd(CTh), FCCP, FACS}

In this issue of the Journal, Molina and colleagues ${ }^{1}$ report an intriguing case series of 100 patients for whom they performed transvascular endosonographic-guided biopsies of mediastinal, hilar, and lung lesions. Using this technique, they achieved a diagnostic accuracy of $74.5 \%$, against a complication rate of only $1 \%$.

The authors need to be congratulated for pushing the clinical limits of what is possible with endobronchial ultrasound- or endoscopic ultrasound-guided biopsies. The technique is bold and allows endoscopists to access intrathoracic lesions that would hitherto have required surgery for biopsy because they lay on the far side of major vessels in the chest. Such intrepid exploration of novel strategies is essential for the healthy development of surgery. In this regard, this paper provides invaluable data on the transvascular endosonographic technique and could potentially be the starting point for its establishment in mainstream practice.

However, if the idea of passing a 21-gauge needle through both walls of the aorta in a conscious patient in an outpatient endoscopy suite sounds intimidating to some readers, it should. Although a good safety record is achieved in this report, the risk of catastrophe has not been fully excluded. What would happen if the patient moved or coughed as a great vessel was punctured? There is no option to put pressure on any bleeding should this occur. If major bleeding occurs, it is unknown how well a patient may tolerate the transfer from the endoscopy suite to the operating room. Although an ultrasound evaluation to rule out hematoma or pseudoaneurysm formation is performed immediately after the procedure, the incidence of vascular complications developing subsequently is not known because these were not looked for (at least 1 patient

\footnotetext{
From Gleneagles Hong Kong Hospital, and International Medical Centre, Hong Kong SAR, China.

Disclosures: Author has nothing to disclose with regard to commercial support.

Received for publication Nov 12, 2019; accepted for publication Nov 12, 2019; available ahead of print Jan 8, 2020

Address for reprints: Alan D.L. Sihoe, FRCSEd(CTh), FCCP, FACS, International Medical Centre, 22 Des Voeux Rd Central, Hong Kong SAR, China (E-mail: asihoe@gmail.com).

J Thorac Cardiovasc Surg 2020;159:2066-7

0022-5223/\$36.00

Copyright (c) 2019 by The American Association for Thoracic Surgery

https://doi.org/10.1016/j.jtcvs.2019.11.075
}

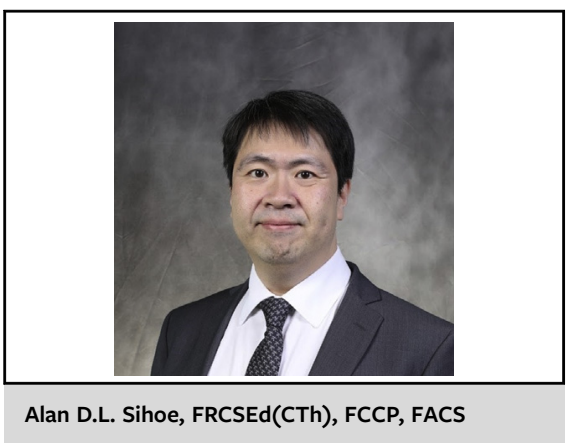

CENTRAL MESSAGE

Promising surgical innovations should be welcomed and studied but perhaps not copied until the evidence matures.

who did undergo computed tomography had a sizeable pseudoaneurysm). With a median follow-up of a year, whether there were delayed vascular sequelae in the longer term is unknown. This paper also does not clarify whether any other similar patients may have received surgical biopsy of similar lesions during the study period, and hence whether the results reflected an element of selection bias. It is further noted that of the 20 patients who had an inadequate yield from biopsies, 10 were lost to follow-up without a final diagnosis. Whether procedure-related events or patients being discouraged from further investigation by their experience were responsible is unclear.

On top of this, it must be remembered that these fine results were obtained by a team of experts. Should readers with less skill or experience attempt the same procedure, there is no guarantee that similar safety can be achieved. The possibility of overzealous surgeons copying a surgical technique after only reading one paper or watching a video is something that should be guarded against. ${ }^{2}$ This phenomenon is perhaps facilitated by modern social media platforms, which allow free uploading of and access to clinical claims and surgical videos that have not been peer-reviewed. ${ }^{3}$ The fact that the paper in this issue has been thoroughly peer-reviewed does not necessarily mean that the editors and reviewers have "endorsed" the transvascular technique. More evidence on this technique is clearly needed-in terms of volume and especially quality. ${ }^{4,5}$ This paper by Molina and colleagues is clearly a commendable step in that right direction. However, until more good-quality evidence becomes available for this 
technique, readers should maybe reconsider whether they should be trying this at home just yet.

\section{References}

1. Molina JC, Chaudry F, Menezes V, Ferraro P, Lafontaine E, Martin J, et al. Transvascular endosonographic-guided needle biopsy of intrathoracic lesions. J Thorac Cardiovasc Surg. 2020;159:2057-65.
2. Sihoe AD, Dunning J. Reasons not to perform subxiphoid video-assisted thoracic surgery. J Vis Surg. 2018;4:214.

3. Hughes K. What role could social media play in surgery? Surgery. 2018;36:671-3.

4. Gonzalez-Rivas D, Damico TA, Jiang G, Sihoe A. Uniportal video-assisted thoracic surgery: a call for better evidence, not just more evidence. Eur J Cardiothorac Surg. 2016;50:416-7.

5. Dunning J. Pioneers, sceptics and those who seek the truth. J Thorac Dis. 2016;8: E1017-8. 